JFFI. 2019; 6(2) 363-367

www.jurnal.farmasi.umi.ac.id/index.php/fitofarmakaindonesia

\title{
PENGARUH TEMPAT TUMBUH DAN LAMA PENYULINGAN SECARA HIDRODESTILASI TERHADAP RENDEMEN DAN PROFIL KANDUNGAN KIMIA MINYAK ATSIRI DAUN KEMANGI (Ocimum canum Sims L.)
}

\author{
Syamsu Nur*, Junaedy Aryanto Baitanu, Sahibuddin A. Gani \\ Departemen Kimia Farmasi, Sekolah Tinggi Ilmu Farmasi Makassar \\ *syamsunur19@gmail.com
}

Submission Date: 08-05-2019; $\quad$ Review Completed: 01-06-2019; $\quad$ Accepted Date: 11-06-2019

\begin{abstract}
Kemangi (Ocimum canum Sims L.) is one of the plants producing essential oils. Kemangi essential oil is taken from the stem and leaves. This study aims to determine the precentage of the yield of kemangi leaf oil and to identify the content of the chemical compounds of essential oils found in kemangi leaves based on the comparison of the place of growth and duration of distillation. Kemangi leaf samples were obtained from the Bontoala sub-district and from Tinggimoncong sub-district of South Sulawesi. The extraction method of essential oils of kemangi leaves is done by the method of distilation/hydrodestilation using three variations of distillation time, namely 6 hours, 12 hours and 18 hours. Based on the results of the study, it can be concluded that the kemangi leaf essential oil which has the highest yield is from Tinggimoncong sub-district of South Sulawesi, which is $3.325 \%$ with distilation time for 18 hours, GC-MS identification results also show that kemangi leaves essential oil from Tinggimoncong subdistrict of South Sulawesi has 93 components of chemical compounds with 5 main components, namely: 5-heptene2-one, 6-methyl, 1,6-octadien-3-ol, 3,7-dimethyl, a-Terpeniol, 2,6-octadienal, 3,7-dimethy (E), eugenoland also has a component of minor compounds, namely: citral, lynalil acetate, eucalyptol, geraniol, verbenol, carveol, and transisoeugenol.
\end{abstract}

Keywords: Daun kemangi; Minyak atsiri; Hidrodestilasi; GC-MS

\section{PENDAHULUAN}

Salah satu tanaman obat herbal yang dewasa ini banyak dimanfaatkan dimasyarakat ialah kemangi (Ocimum canum Sims L.). Di masyarakat, kemangi digunakan sebagai sayur atau lalap. Selain sebagai lalapan, kemangi juga mempunyai khasiat mengatasi bau mulut, bau badan, badan lesu, anti peradangan, antibiotik alami, diuretik, analgesik, melancarkan peredaran darah, membersihkan racun, antimalaria, nyeri haid, antijamur, mencegah kanker dan kolesterol (Ozcan and Chalchat, 2002, Nuzulia and Santoso, 2017, Hendrawati and Eka, 2010). Bagian dari tanaman kemangi yang digunakan untuk pengobatan tersebut yaitu daun dan bunga. Secara turun temurun, minyak kemangi juga banyak digunakan sebagai aromatik, antispasmodik, dan aktivitas lainnya (Marwat et al., 2011, Ozcan and Chalchat, 2002).

Pada tanaman kemangi memiliki banyak kandungan kimia antara lain saponin, flavonoid, tanin, dan minyak atsiri (Muchtaridi, 1996). Berdasarkan hasil analisis GC-MS memperlihatkan bahwa minyak atsiri yang berasal dari kemangi terdiri dari 54 komponen, dengan 9 komponen utama yang memiliki kandungan diatas $2 \%$, ke 9 komponen utama tersebut adalah linalool (2,03\%), Z-sitral $(7,02 \%)$, geranial $(7,86 \%)$, metil eugenol $(4,88 \%), 3-$ metilsiklopent-2-enona (3,78\%), asam metil heksadekanoat $(2,48 \%)$, etil 9-oktadekenoat $(10,62 \%)$, asam etil heksadekanoat $(17,72 \%)$, dan asam etil oktadekanoat (14,83\%) (Sulianti, 2008).

Minyak atsiri atau minyak eteris pada mulanya adalah istilah yang digunakan untuk minyak mudah menguap yang diperoleh dari tanaman dengan cara penyulingan uap. Istilah ini, dimaksudkan untuk membedakan minyak lemak dengan minyak atsiri yang berbeda tanaman penghasilnya. Minyak atsiri dapat diproduksi melalui beberapa metode. Namun sebagian besar minyak atsiri diperoleh melalui metode penyulingan yang dikenal juga dengan hidrodestilasi. Cara lain yang perlu diketahui yaitu metode ekstraksi yang menggunakan pelarut dan metode pengempaan. Dari ketiga metode pengolahan tersebut, cara paling praktis dan efisien adalah metode penyulingan. Hal ini dikarenakan metode penyulingan hanya memerlukan biaya produksi lebih 
murah dibanding metode pengolahan lain, selain biaya yang diperlukan relatif murah, rendemen minyak atsiri yang dihasilkan juga cukup memadai, dan mutunya dapat diterima dengan baik oleh konsumen (Sastrohamidjojo, 2014, Negoro, 2007).

Menurut (Haris, 1987) faktor-faktor yang mempengaruhi rendemen minyak atsiri adalah jenis bahan baku, ukuran dan mutu bahan baku, peralatan yang digunakan, ketelitian dan pelaksanaan penyulingan. Namun dari hasil penelitian sebelumnya yang dilakukan oleh (Ulfah and Karsa, 2007), menyatakan bahwa tempat tumbuh dan lama penyulingan juga dapat mempengaruhi rendemen minyak atsiri.

Berdasarkan uraian tersebut dilakukan penelitian tentang pengaruh tempat tumbuh dan lama penyulingan terhadap rendemen minyak atsiri daun kemangi (Ocimum canum Sims L.) dengan metode hidrodestilasi serta mengidentifikasi kandungan kimia minyak atsirinya.

\section{METODE PENELITIAN}

\section{A. Alat dan Bahan}

Alat-alat yang digunakan antara lain: seperangkat alat hidrodestilasi, peralatan gelas (pyrex), timbangan analitik, instrumen GC-MS (TRACE 1310 Gas Chromatograph dan ISQ Single Quadrupole $M S$ ), dan corong pisah.

Bahan yang digunakan dalam penelitian ini adalah daun kemangi segar (Ocimum canum Sims L.), aquadest, n-heksan (Merck, Germany), dan $\mathrm{Na}_{2} \mathrm{SO}_{4}$ (Merck, Germany).

\section{B. Cara Kerja}

Penyiapan sampel dan proses Hidrodestilasi

Proses pengambilan daun kemangi dilakukan pada sore hari, diambil daun yang masih mudah dan segar, dilakukan sortasi basah untuk memisahan kotoran-kotoran atau bahan asing lainya dari sampel kemudian dicuci dengan air mengalir dan ditiriskan. Sampel daun kemangi yang diperoleh dari dua tempat yang berbeda ditimbang masing-masing 150 gram untuk tiap sampel. Proses penyulingan menggunakan tiga variasi perbandingan waktu yakni selama 6 jam, 12 jam dan 18 jam. Minyak atsiri yang diperoleh dihilangkan kandungan airnya dengan menambahkan serbuk $\mathrm{Na}_{2} \mathrm{SO}_{4}$ anhidrat sedikit demi sedikit hingga $\mathrm{Na}_{2} \mathrm{SO}_{4}$ terapung (Sulianti, 2008). Dihitung persen rendemen dari minyak atsiri yang diperoleh. Rendemen minyak atsiri daun kemangi dihitung dalam $\% \mathrm{~b} / \mathrm{b}$

$$
\text { Rendemen } \%=\frac{\text { berat minyak atsiri }}{\text { berat penimbangan bahan }} \times 100 \%
$$

\section{Karakterisasi Minyak Atsiri Daun Kemangi}

Satu tetes minyak atsiri diteteskan pada sepotong kertas saring. Bila dibiarkan, maka minyak atsiri akan menguap dengan sempurna tanpa meninggalkan noda transparan. Minyak atsiri yang dihasilkan diperiksa secara organoleptis meliputi bau, rasa, dan warna. Pemeriksaan warna dilakukan secara visual. Untuk pemeriksaan bau pada kertas saring ditetesi beberapa tetes minyak atsiri daun kemangi kemudian dikipas-kipas sambil dicium baunya (Guenther, 1990).

Identifikasi Kandungan Minyak Atsiri Daun Kemangi dengan Kromatografi GasSpektrometri Massa (GC-MS)

Identifikasi kandungan senyawa kimia dengan kromatografi gas-spektrometri massa untuk minyak atsiri daun kemangi dilakukan dengan cara minyak atsiri daun kemangi sebanyak 1,00 $\mu 1$ diinjeksikan otomatis kedalam kedalam kolom dengan kondisi suhu $280^{\circ} \mathrm{C}$ melalui kolom kapiler Thermo TG-5MS sepanjang 30 meter yang berada di dalam oven dengan suhu yang stabil yaitu $330^{\circ} \mathrm{C}$. Proses pembacaan puncak dan penentuan spektra massa dilakukan pada kromatogram yang tampak pada alat kromatografi gas-spektrometri massa.

\section{Data Analisis}

Analisis data dapat dilakukan dengan cara menghitung persentase rendemen minyak atsiri dari berbagai perbandingan tempat tubuh dan lama penyulingan, selanjutnya diidentifikasi secara kualitatif senyawa aktif menggunakan gass chromatography mass / mass spectrometry (GC-MS), hasil identifikasi diperoleh berdasarkan waktu retensi dan spektra massa sampel dibandingkan dengan spektra massa senyawa standar berdasarkan data bank dari NIST library (Dacosta et al., 2017, Khajiamiri, 2010).

\section{HASIL DAN PEMBAHASAN Rendemen Minyak Atsiri}

Sampel yang digunakan dalam penelitian ini adalah daun kemangi segar sebanyak 300 gram yang diperoleh dari dua tempat yang berbeda yakni dari kecamatan Bontoala kota Makassar dan dari kecamatan Tinggimoncong Sulawesi Selatan Proses penyulingan dilaksanakan dengan tiga variasi perbandingan waktu yakni selama 6 jam, 12 jam, dan 18 jam. Tujuan dilakukan variasi perbandingan waktu penyulingan adalah untuk mendapatkan hasil rendemen yang ideal diantara ketiga perbandingan waktu tersebut. Proses penyulingan dilakukan dengan cara sampel daun kemangi dicampur dengan akuades dalam labu destilasi dan dipanaskan. Waktu destilasi terhitung mulai dari hasil tetesan pertama yang diperoleh. Setelah mencapai waktu yang ditentukan, peralatan destilasi dihentikan dan minyak atsiri yang 
dihasilkan kemudian ditampung dan disiapkan untuk proses pemurnian.
Minyak atsiri daun kemangi murni yang diperoleh kemudian dihitung persen rendemennya menggunakan rumus $\% \mathrm{~b} / \mathrm{b}$.

Tabel 1. Hasil hidridestilasi minyak atsiri daun kemangi (Ociumun sanctum)

\begin{tabular}{cccc}
\hline Faktor A & \multicolumn{3}{c}{ Rendemen (\%) } \\
(Tempat Tumbuh) & B1 (6jam) & B2 (12 jam) & B3 (18 jam) \\
\hline A1 (Kecamatan Bontoala Kota \\
$\begin{array}{c}\text { Makassar) } \\
\text { A2 (Kecamatan Tinggimoncong } \\
\text { Sulawesi Selatan) }\end{array}$ & 0,7234 & 2,3012 & 2,5938 \\
\hline
\end{tabular}

Dari hasil perhitungan rendemen minyak atsiri daun kemangi maka diperoleh, presentase rendemen minyak atsiri yang besar adalah pada B3 atau pada waktu penyulingan selama 18 jam untuk setiap faktor tempat tumbuh dari sampel. Hal ini dikarenakan semakin lama proses penyulingan maka semakin banyak pula minyak atsiri yang diperoleh. Oleh karena itu diambil minyak atsiri dengan presentase terbesar dari setiap tempat tumbuh, dan dari setiap perbandingan waktu penyulingan yaitu minyak atsiri dari kecamatan Tinggimoncong Sulawesi Selatan dengan lama penyulingan selama 18 jam, untuk diidentifikasi kandungan senyawa kimianya menggunakan GC-MS.

Namun jika ditinjau dari efisiensi dan efektivitas proses penyulingan menunjukkan bahwa faktor A1 nilai presentase idealnya berada pada proses penyulingan selama 18 jam (B3) dengan presentase rendemen sebesar 2,593, sedangkan untuk faktor A2 berdasarkan data rendemen yang diperoleh sudah ideal pada proses penyulingan selama 12 jam (B2) dengan presentase rendemen sebesar 2,991 dan tidak berbeda signifikan dengan faktor B3 serta memiliki persen rendemen yang lebih tinggi dari sampel A1.

\section{Karakterisasi Minyak Atsiri Daun Kemangi}

Pemeriksaan minyak atsiri secara umum dilakukan dengan meneteskaan satu tetes minyak astiri pada kertas saring, bila dibiarkan maka minyak atsiri akan menguap dengan sempurna tanpa meninggalkan noda transparan. Hasil pemeriksaan sebagai berikut:

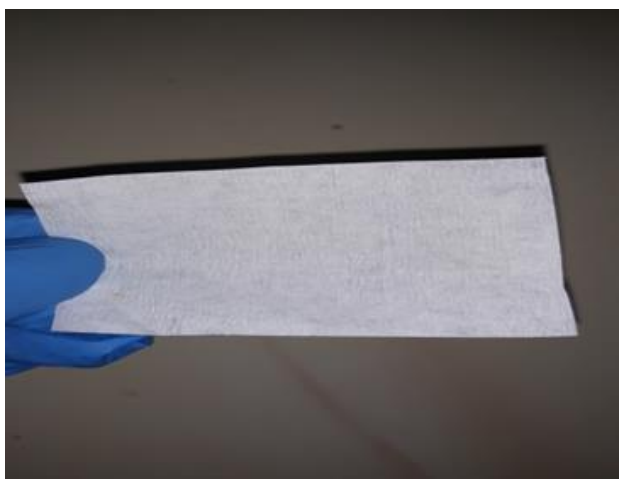

B

Gambar 1. Karakterisasi minyak atsiri Setelah diteteskan minyak atsiri (A) dan setelah minyak atsiri menguap dan tidak meninggalkan noda (B).

Berdasarkan hasil pemeriksaan minyak atsiri secara kualitatif dengan cara identifikasi minyak atsiri secara umum pada sampel daun kemangi pada Gambar 1 menunjukan sampel daun kemangi yang diperoleh dari kecamatan Bontoala, kota makassar dan dari kabupaten Gowa, Sulawesi Selatan merupakan minyak atsiri.
Pemeriksaan organoleptis minyak atsiri daun kemangi merupakan proses identifikasi umum. Pemeriksaan organoleptis yang dilakukan meliputi bau, rasa, dan warna. Hasil identifikasi diketahui minyak atsiri daun kemangi memilki bau khas tanaman kemangi, memiliki rasa pedas dan cenderung bening dan berwarna kekuning-kuningan. 


\section{Hasil Identifikasi Minyak Atsiri Daun Kemangi dengan Kromatografi Gas-Spektrometri Massa (GC-MS)}

Identifikasi menggunakan kromatografi gasspektrofotometri massa bertujuan untuk mengetahui jumlah kandungan senyawa yang terdapat dalam minyak atsiri daun kemangi, yang berasal dari kecamatan Bontoala kota Makassar dan kabupaten Gowa Sulawesi Selatan. Minyak atsiri daun kemangi sebanyak $1,00 \mu 1$ diinjeksikan otomatis kedalam kolom dengan suhu $280^{\circ} \mathrm{C}$ yang telah dialiri gas helium. Minyak atsiri tersebut dalam bentuk gas bersama gas helium (fase gerak) melalui kolom kapiler Thermo TG-5MS sepanjang 30 meter yang berada di dalam oven dengan suhu yang stabil yaitu $330^{\circ} \mathrm{C}$, didalam kolom terjadilah pemisahan komponen-komponen senyawa yang terdapat didalam minyak atsiri daun kemangi kemudian komponen-komponen senyawa tersebut akan masuk kedalam detektor spetrometri massa dan direkam oleh rekorder, disini senyawa-senyawa akan terbaca sebagai kromatogram, puncak kromatogram yang dihasilkan dibandingkan dengan waktu retensi standar dan spektrum massa, kemudian molekulmolekul yang diperoleh dalam bentuk kromatogram akan terbaca oleh spektofotometer massa, dengan cara menangkap, mengionisasi, dan mendeteksi molekul yang terionisasi dan akan mendeteksi fragmen-fragmen dalam menentukan rasio setiap analit yang terdapat dalam minyak atsiri daun kemangi, seperti yang dapat dilihat pada Tabel 2 dan 3 sebagai berikut :

Tabel 2. Identifikasi komponen senyawa berdasarkan prediksi produk ion dari minyak atsiri daun kemangi yang diambil dari kecamatan Bontoala kota Makassar

\begin{tabular}{|c|c|c|c|c|}
\hline Senyawa & tR (menit) & Prediksi $(\mathbf{m} / \mathbf{z})$ & Probability (\%) & Referensi \\
\hline 5-hepten-2-on, 6-metil & 4,57 & $\begin{array}{c}53,55,58,69,71,77,83 \\
93,97,108,126\end{array}$ & 81,7 & $\begin{array}{l}\text { NIST dan } \\
\text { Wiley }\end{array}$ \\
\hline $\begin{array}{c}\text { 1,6-octadien-3-ol, 3,7- } \\
\text { dimetil }\end{array}$ & 5,39 & $\begin{array}{c}53,55,65,67,69,71,80 \\
83,86,93,96,107,121 \\
127,136,154\end{array}$ & 83,9 & Library \\
\hline $\begin{array}{l}\text { 2,6-octadienal, 3,7- } \\
\text { dimetil (E) }\end{array}$ & 6,59 & $\begin{array}{c}53,59,67,69,74,84,91 \\
94,109,123,137,152\end{array}$ & 59,1 & \\
\hline asam geranic & 7,12 & $\begin{array}{c}53,69,82,91,100,123 \\
149,163,16\end{array}$ & 65,8 & \\
\hline
\end{tabular}

Tabel 3. Identifikasi komponen senyawa berdasarkan prediksi produk ion dari minyak atsiri daun kemangi yang diambil dari kecamatan Tinggimoncong, Sulawesi Selatan

\begin{tabular}{|c|c|c|c|c|}
\hline Senyawa & tR (menit) & Prediksi $(\mathbf{m} / \mathbf{z})$ & Probability (\%) & Referensi \\
\hline 5-hepten-2-on, 6-metil & 4,58 & $\begin{array}{c}53,55,58,69,71,77,83, \\
93,108,126\end{array}$ & 79,8 & $\begin{array}{c}\text { NIST dan } \\
\text { Wiley }\end{array}$ \\
\hline $\begin{array}{c}\text { 1,6-octadien-3-ol, 3,7- } \\
\text { dimetil }\end{array}$ & 5,40 & $\begin{array}{c}53,55,65,67,69,71,80 \\
83,86,93,96,107,121 \\
127,136,154\end{array}$ & 85,2 & Library \\
\hline$\alpha$-terpeniol & 6,09 & $\begin{array}{c}55,59,65,67,71,74,79 \\
81,88,93,95,107,121 \\
136,139,153\end{array}$ & 59,0 & \\
\hline $\begin{array}{l}\text { 2,6-octadienal, 3,7- } \\
\text { dimetil (E) }\end{array}$ & 6,58 & $\begin{array}{c}53,59,67,69,74,84,91 \\
94,109,123,137,152\end{array}$ & 72,9 & \\
\hline Eugenol & 7,25 & $\begin{array}{c}51,55,65,69,74,77,83, \\
91,94,103,115,121,13 \\
1,137,149,164\end{array}$ & 38,3 & \\
\hline
\end{tabular}


Berdasarkan hasil identifikasi kandungan senyawa kimia menggunakan GC-MS terhadap sampel minyak atsiri daun kemangi asal kecamatan Bontoala kota Makassar maka diperoleh 68 komponen senyawa kimia yang terkandung dalam sampel, dengan 4 komponen utamanya, yaitu: 5hepten-2-on, 6-metil, 1,6-octadien-3-ol, 3,7-dimetil, 2,6-octadienal, 3,7-dimetil (E), asam geranic, dan juga memiliki komponen senyawa minor (persen probabilitas >5\%) diantaraya: sitral, verbenol, carveol, lynalil asetat, eucalyptol, dan geraniol serta senyawa lainnya dengan persen probabilitas $<1 \%$ (data tidak dipublikasikan). Sedangkan sampel minyak atsiri daun kemangi asal kecamatan Tinggimoncong Sulawesi Selatan memiliki 93 komponen senyawa kimia dengan 5 komponen utamanya yaitu: 5-hepten-2-on, 6-metil, 1,6octadien-3-ol, 3,7-dimetil, $\alpha$-terpeniol, 2,6octadienal, 3,7-dimetil (E), eugenol dan juga memiliki komponen senyawa minor dengan persen probabilitas $>5 \%$ yaitu: sitral, Linalil asetat, eucalyptol, geraniol, verbenol, carveol, transisoeugenol dan senyawa lainnya dengan persen probabiltas $<1 \%$ (data tidak dipublikasikan). Berdasarkan dari hasil identifikasi kandungan senyawa kimia minyak atsiri daun kemangi dari profil GC-MS menunjukkan adanya perbedaan profil kandungan kimia berdasarkan tempat tumbuhnya. Sampel minyak atsiri yang berasal dari daerah Kecamatan Tinggimoncong memberikan profil senyawa yang besar dibandingkan dari daerah Kecamatan Bontoala. Hal ini menunjukkan bahwa perbedaan tempat tumbuh dapat mempengaruhi persen rendemen dan profil kandungan kimia minyak atsiri dari suatu sampel kemangi.

\section{KESIMPULAN}

Berdasarkan hasil penelitian maka dapat disimpulkan bahwa minyak atsiri daun kemangi yang memiliki rendemen paling besar adalah sampel daun kemangi yang berasal dari Kecamatan Tinggimoncong Sulawesi Selatan sebesar 3,325\% dengan waktu penyulingan selama 18 jam. Sedangkan hasil identifikasi kandungan senyawa kimia dengan menggunakan GC-MS juga menunjukkan bahwa minyak atsiri daun kemangi dari Kecamatan Tinggimoncong Sulawesi Selatan memiliki 93 komponen senyawa kimia dengan 5 komponen utamanya yaitu: 5-hepten-2-on, 6-metil, 1,6-octadien-3-ol, 3,7-dimetil, $\alpha$-terpeniol, 2,6octadienal, 3,7-dimetil, eugenol dan juga memiliki komponen senyawa minor, yaitu: sitral, lynalil asetat, eucalyptol, geraniol, verbenol, carveol, dan transisoeugenol.

\section{DAFTAR PUSTAKA}

Dacosta, M., Sudirga, S. K. \& Muksin , I. K. 2017. Perbandingan Kandungan Minyak Atsiri Tanaman Sereh Wangi (Cymbopogon nardus L, Rendle) yang Ditanaman di Lokasi Berbeda. Jurnal Simbiosis V, 5, 2531.

Guenther, E. 1990. Minyak Atsiri Jilid IV B, Jakarta, UI-Press.

Haris, R. 1987. Tanaman Minyak Atsiri, Jakarta, Penebar Swadaya.

Hendrawati \& Eka, R. A. 2010. Uji Toksisitas Akut Ekstrak Etanol Daun Kemangi (Ocimum sanctum Linn.)Terhadap Larva Artemia salina Leach Dengan Metode Brine Shrimp Lethality Test (BST). Skripsi, Universitas Diponegoro.

Khajiamiri 2010. Identifikasi Senyawa Aktif menggunakan GC-MS berdasarkan keputusan Wiley and NIST Library. USA.

Marwat, S. K., Rehman, F. U., Khan, S. M., Ghulam, S., Anwar, N., Mustafa, G. \& Usman, K. 2011. Phytochemical Constituents and Pharmacological Activities of Sweet Basil Ocinum basilicum L (Lamiaceae). Asian Journal of Chemistry, 23, 3773-3782.

Muchtaridi, M. 1996. Penelitian Pengembangan Minyak Atsiri sebagai Aroma Terapi dan Potensinya sebagai Produk Sediaan Farmasi.

Negoro, A. M. 2007. Penentuan metode terbaik proses penyulingan minyak atsiri daun sirih [Piper betle linn.] antara penyulingan dengan air dan penyulingan dengan air dan uap. Skripsi, Universitas Sanata Dharma.

Nuzulia, R. \& Santoso, O. 2017. Pengaruh Ekstrak Daun Kemangi (Ocimum basilicum Linn) pada Berbagai Konsentrasi terhadap Viabilitas Bakteri Streptococcus mutans: Studi pada Mahasiswa Fakultas Kedokteran Universitas Diponegoro. Jurnal Kedokteran Diponegoro, 6, 1565-1571.

Ozcan, M. \& Chalchat, J. C. 2002. Essential Oil Composition of Ocimum basilicum L.and Ocimum minimum L. in Turkey. Czech J. Food Sci, 6, 223-228.

Sastrohamidjojo, H. 2014. Kimia Minyak Atsiri, Yogyakarta, Gadjah Mada University Press.

Sulianti, S. B. 2008. Studi Fitokimia Ocimum Spp.: Komponen Kimia Minyak Atsiri Kemangi Dan Ruku-ruku (Phytochemical Study of Ocimum Spp.: Chemical Components of Essential Oils of Kemangi and Ruku-ruku). Berita Biologi LIPI, 9, 237-241.

Ulfah, D. \& Karsa, A. L. 2007. Pengaruh tempat tumbuh dan lama penyulingan rendemen 
minyak atsiri rambu atap (Baeckea frustescens) dengan penyulingan metode perebusan. Jurnal Hutan Tropis Borneo, 08, 84-88. 